\title{
EUPHA 10 years: the annual conference
}

Jouke Van der Zee $\cdot$ Madelon Kronemann $\cdot$ Tina Dorn

\section{Introduction}

The annual conference forms one of EUPHA's main activities. It is one of the two 'pillars' of EUPHA, so to say. The second pillar is the European Journal of Public Health. The annual conference has in common with the Journal that the conferences already existed before EUPHA was officially founded. In 1989 NIVEL, the Netherlands Institute of Health Services Research, organised the first European Health Services Research meeting near Utrecht in the Netherlands in order to create an international platform for Health Services researchers and also for Public Health research. These Health Services Research conferences continued in 1990 (Cologne), 1991 (London) and 1992 (Paris) while the preparation for the foundation of EUPHA progressed. Even the 1993 conference (in Maastricht) was not yet a full EUPHA conference. The first genuine EUPHA conference was the conference in Copenhagen in 1994. So the Dresden conference is actually the ninth EUPHA conference and not the tenth.

\section{Health Services Research and Public Health Research}

The EUPHA conferences started as Health Services Research conferences; after EUPHA's foundation the focus gradually shifted to Public Health Research. The similarities and differences between the two types of research can be shown in a simple Venn-diagram (see graph 1).

In category I elements of the health services are studied without taking health (effects) into account (a study about remuneration of General Practitioners, for example). In category II (public) health is the research subject without taking health services into account (prevent adolescents to start smoking in schools). Category III forms the overlapping category: here the influence of 'health services' on 'health' forms the topic. EUPHA deals with the whole range of research subjects; Health services research forms an integrated part of EUPHA.

EUPHA conferences circulate through Europe with the rotating EUPHA-presidency according to a NEWS (North, East, West, South) scheme. Until the year 2000 the EUPHApresident acted as organiser and host to the conference; after 2000 it is the president-elect (next year's EUPHA president) who is charge of the conference. The aim of the conference is to provide a platform for researchers to present their work to research-colleagues and other interested conference-participants like policy-makers or public health practitioners. The most common way to participate as a researcher is by submitting an abstract for a poster or an oral presentation; since 1999 abstract submission for workshops is possible, too. 


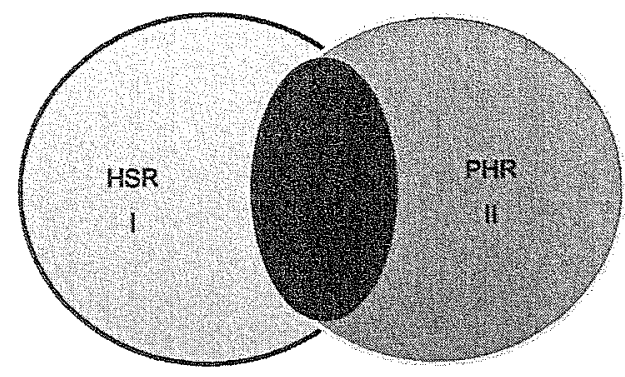

\section{HSR without health outcomes \\ II. Public Health without health services \\ III. a) HSR with health outcomes \\ b) PHR with health services included}

Fig. 1. Venn-diagram of similarities and differences between Health Services Research and Public Health Research

Abstracts are being judged by an international Scientific Committee, whose members score at least 100 to 150 abstracts and in some cases the total number of the abstracts on a 5 point scale (the score 5 represents excellent quality, the score 1 very low quality). These scores form the base of the decisions about acceptance and rejection of the abstracts ${ }^{1}$. Each abstract is rated by an average of 5-10 judges, which produces rather robust rates. The scientific committee consists of approximately 25 'permanent' members (one per EUPHA member country), who, in principle, serve two three-year terms, completed each year by a group of approximately 5 local members, who participate one year only. The chair of the committee is appointed by the local organizer; he/she starts one year in advance and remains another year in the committee in order to communicate local experiences.

A jubilee is mostly a moment of reflection on the past and glances into the future. EUPHA's 10th anniversary forms a good occasion to show how both the abstract submission and the evaluation developed over this 9 -year period. As a reflection on the past, we would like to know what was achieved in the past conferences. We were curious who did submit papers and about what subjects and whether there could be demonstrated a development in subjects over the years. We also would like to gain insight in what the judges apparently find important features of the abstracts. In other words: what should an abstract look like to obtain a high score. As a glance in the future, we could give tips to improve future abstracts.

The EUPHA-office kept both the abstracts and the ratings of the judges as an electronic data-file for all the nine conferences since 1994. These files provided the basis to answer the following questions:

\footnotetext{
${ }^{1}$ The decision rules about acceptance or rejection of the abstracts are basically that the highest ranking $25 \%$ are accepted for oral presentation without discussion and the lowest ranking $25 \%$ are rejected. If, after this selection, there still is room left for oral presentations the second highest quartile jected. serves as a source for further selection. This additional section anced distribution of the selected abstracts over the countries of origin of the (first) authors.
} 


\section{Research Questions}

1. How did the number and origin of the submitted abstracts develop over the period 1994-2002 and what is the relationship between the conference location and the origin of the submitted abstracts?

2. What is the development in space (that is over the countries) and over time of the evaluation of the abstracts?

3. Can we identify determinants of the abstract evaluation? Can we answer the question what distinguishes a 'good' from a 'bad' abstract?

\section{Method}

The first two research questions will be answered by analysing the total database (that is the database with all the abstracts) with all submitted abstracts ${ }^{2}$ and all judgements.

This database contains the following elements:

A conference year, location and conferencetheme (identical for all abstracts of a given conference)

B country of origin of the first author

C score of the judges

D outcome: acceptance for oral presentation, poster presentation or rejection

For answering the third research question (determinants of the average rating) abstracts of several years (the first two years $(1994,1995)$ and the last three years $\left(2000,2001,2002^{3}\right)$ ) were coded by the authors of this paper ${ }^{4}$.

A scoring form (see Table 2) was developed to code the following characteristics:

A formal qualities of the abstract

does it follow the guidelines for a structured abstract

is it in English or in another language

is it legible or generally comprehensible

B Study Design

quantitative/qualitative

descriptive/(systematically) comparative

local/national/international scope

C Topic/subject of the study

Fits this year's conference motto yes/no

Fits last year's conference motto yes/no

- Topic classification into 5 main categories: Health services research/Epidemiology/ Health promotion/Health information or Methodology

- Disease related study or not disease related

\footnotetext{
${ }^{2}$ Only abstracts submitted for single presentations were selected for analysis; workshops were excluded (these were introduced in 1999).

${ }^{3}$ Originally when this study started the years 2000 and 2001 were the last two years. Later, the abstracts of 2002 have been added in order to provide an up-to-date overview at the Dresden conference.

${ }^{4}$ The data for 1994/1995 and 2000/2001 have been described in Tina Dorn's MPH thesis at Maastricht University: Dorn, Tina, Developments in European Public Health Research: towards more "new" Public Health? Maastricht University, MPH thesis, 2001.
} 


\section{Scoring procedure and inter judge reliability}

The three authors of this paper all scored one third of the abstracts by means of the scoring form. The scoring on this form does not say anything about the quality of the abstract, but deals with structural parameters and the subject of the study (see above). In order to establish the inter-rater reliability among the authors, a set of 20 abstracts was scored by all three authors (Dorn, 2001, p 25). Cohen's Kappas were calculated as an indicator of the reliability. In total 18 categories have been scored (overall total of agreements: $3 \times 18=54$ ) Of these 54 possible agreements $18(33 \%)$ were above 0.75 (very good agreement) and 6 (11\%) below 0.40 (low agreement); the other 30 had kappa's between 0.40 and 0.75 . Agreement was especially low around classifying an abstract under the topic 'health promotion' and its subcategories (health education and policy). One of the three judges systematically deviated from the other two in this respect. A more comprehensive set of instructions and discussion among the raters was undertaken to improve the agreement on this point. For the rest the inter rater reliability was considered as sufficient.

\section{Analysis}

A multiple regression analysis (OLS) was performed with the average scoring (1 to 5 point scale) of the abstract by all the judges as the dependent variable and the above mentioned factors as independent variables. With polytomous variables one of the categories was used as reference category (see results section). Two analyses were performed: one with the scoring form variables only and one with the addition of two other variables, extracted from the general database: the year of the conference $(1994:-2,1995:-1), 2000:+1,2001$ : $+2,2002:+3)$ and the region where the first author of the paper could be located (grouped into the following categories: North-West Europe (Scandinavia, UK, The Netherlands, Ireland), West-Central Europe (Belgium, France, Germany, Switzerland, Austria), Southern Europe (Portugal, Spain, Italy, Greece, Malta), Eastern Europe (Czech/Slovak republic, Baltic states, Romania, Bulgaria, Turkey, former Yugoslavia, Newly Independent States), NonEuropean countries (USA, Canada, India, Australia, Africa).

\section{Results}

\section{Conference location and participation ${ }^{5}$}

The first general research question: 'How did the number and origin of the submitted abstracts develop over the period 1994-2002 and what is the relationship between the conference location and the origin of the submitted abstracts?' was specified into the following sub-questions:

1a: To what extent does the place where the conference is held influence the participation from that region in the year of the conference?

$1 b$ : In case of a positive relationship between conference venue and participation from the region; does it remain the following year(s)?

\footnotetext{
${ }^{5}$ When we use the term 'participation' we actually mean 'abstract submission'; we do not dispose of detailed information about the conferences' participants.
} 


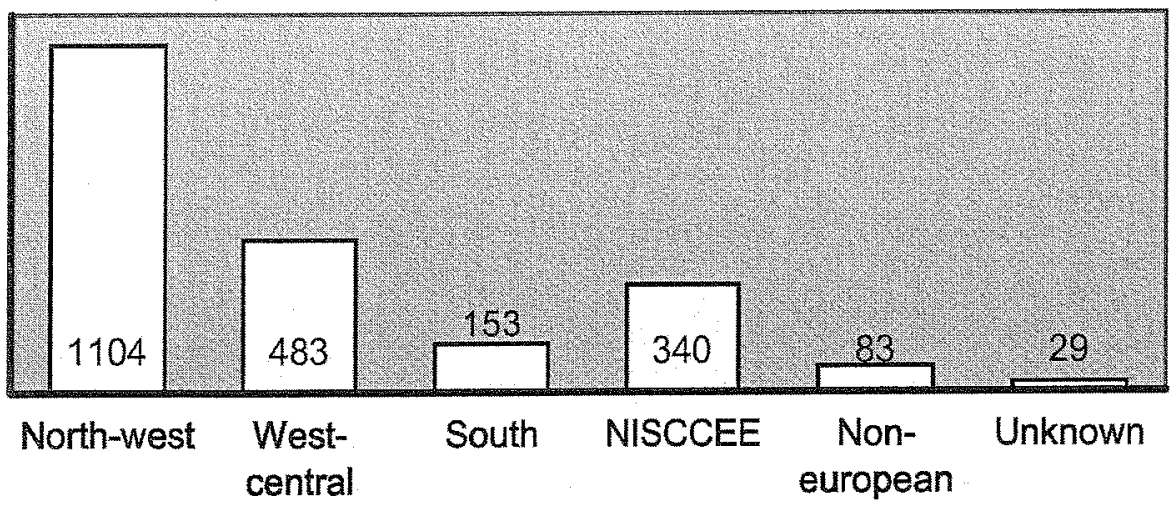

Fig. 2. Regional subdivision of the submitted abstracts over the period 1994-2002

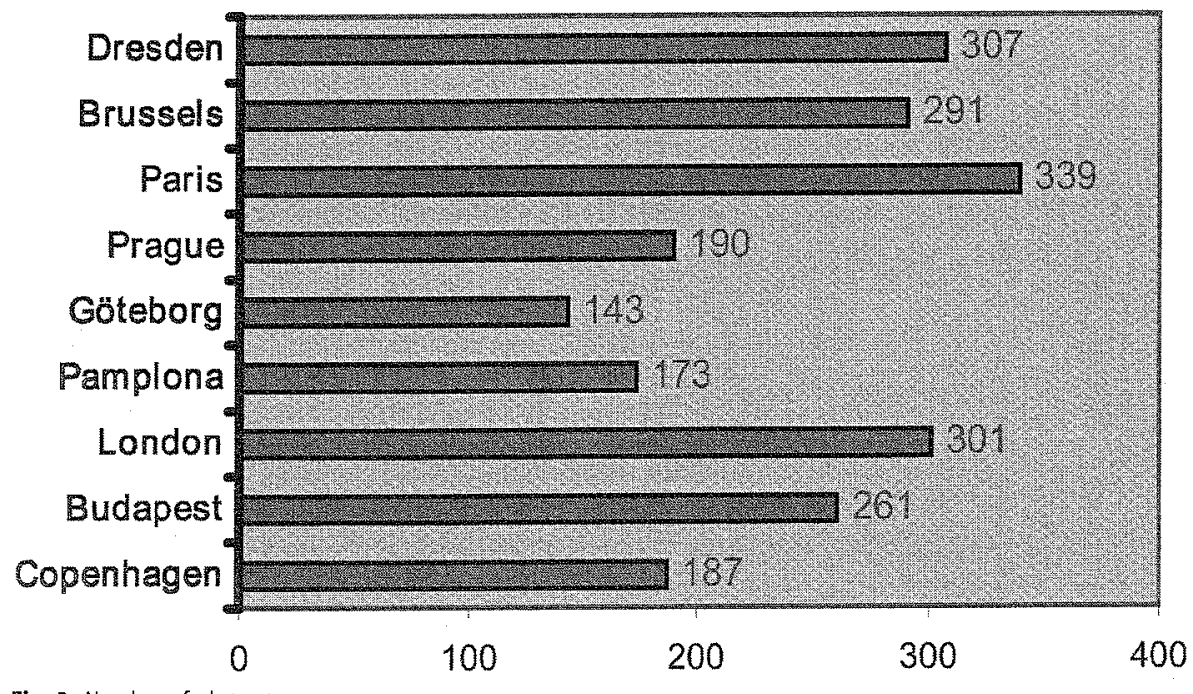

Fig. 3. Number of abstracts per year

A good argument for rotating the conference would be that it stimulates participation from the region; it would even be better if an increased participation would continue in the next or following years. In Graph 2 the regional subdivision of the submitted abstracts over the period 1994-2002 is displayed.

The number of abstracts increased gradually in the years 1994-1996; Pamplona 1997 and Gothenburg 1998 had a lower attractiveness, but the increase started again from 1999 (Prague) till Paris (2000), Brussels (2001) and Dresden (2002) (Graph 3). The influence of the conference venue on the participation is clearly visible; the participation from the host country (Graph 4) is considerably higher in the conference year than before or after. The long(er) term effect of a specific location (as expressed as the percentage of abstracts from a specific host-country) does not seem to be substantial. The effect is limited to the year of the conference. 


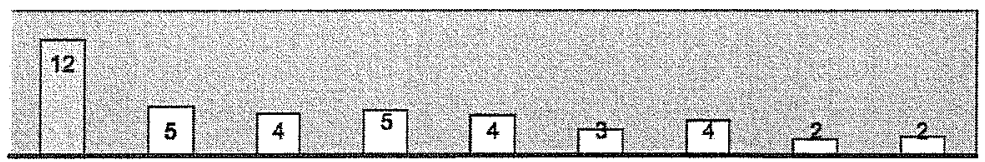

Denmark

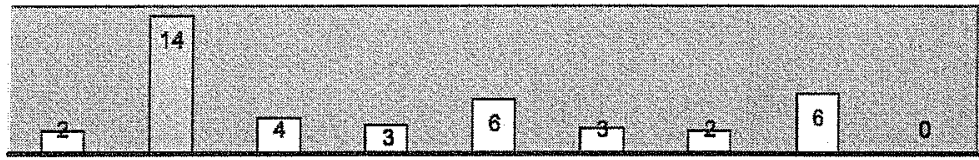

Hungary

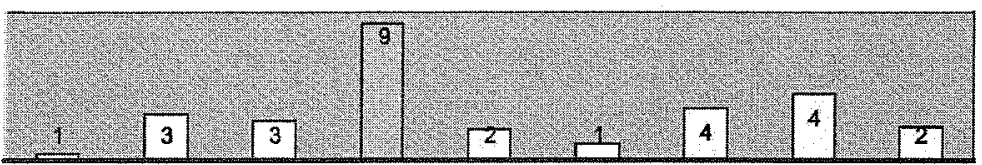

Spain



France

Fig. 4. Participation from countries that hosted the conference

\section{The judgements}

Research question 2: 'What is the development in space and time of the average judgements of the conference abstracts?' has been split up into three sub-questions:

2a: Did the average judgements improve over time?

2b: Are there regional differences in the abstracts judgements?

2c: Do the scores of ad hoc judges (recruited annually from the host countries) differ systematically from the scores of the permanent members of the scientific committee?

The overall average of the 2190 abstracts was 3.17 ; slightly above the mathematical average of a 1 (bad) to 5 (good) scale. In Graph 5 the average over the years is shown. Some conferences receive a higher overall appreciation (Budapest, 1995; Göteborg, 1998) than others (London, 1996; Paris, 2000) but there seems to be no trend in time. The only thing that can be said is that the annual averages regress somewhat to the grand mean.

The geographical spread of the average judgements over Europe is shown on Graph 6 and 7. Countries that had submitted less than 5 abstracts in the period 1994-2002, were left blank.

High averages are found in North-West Europe (with the exception of Ireland and, to some extent, Norway). The lowest rates are found in South-East Europe (Balkan, Turkey). Italy, the Czech Republic have also rather highly rated abstracts. Abstracts from non-European countries like Canada and the USA have high ratings, too. For some countries, that submitted a sufficient number of abstracts (90 abstracts over 9 years), we could see whether there was any progress in the rates (Graph 8). Three patterns could be observed. For some countries (Denmark, Sweden and the United Kingdom) the average rates progressed gradually. For Finland, Germany, Hungary and the Netherlands ratings fluctuated 


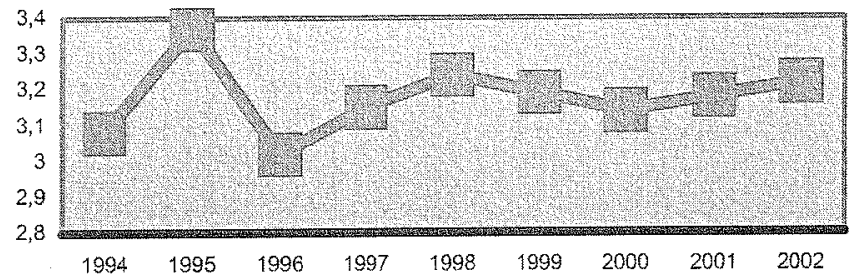

Fig. 5. Mean score per conference, development over time

Fig. 6. Mean score of abstracts per country

Fig. 7. Map of Europe with mean scores
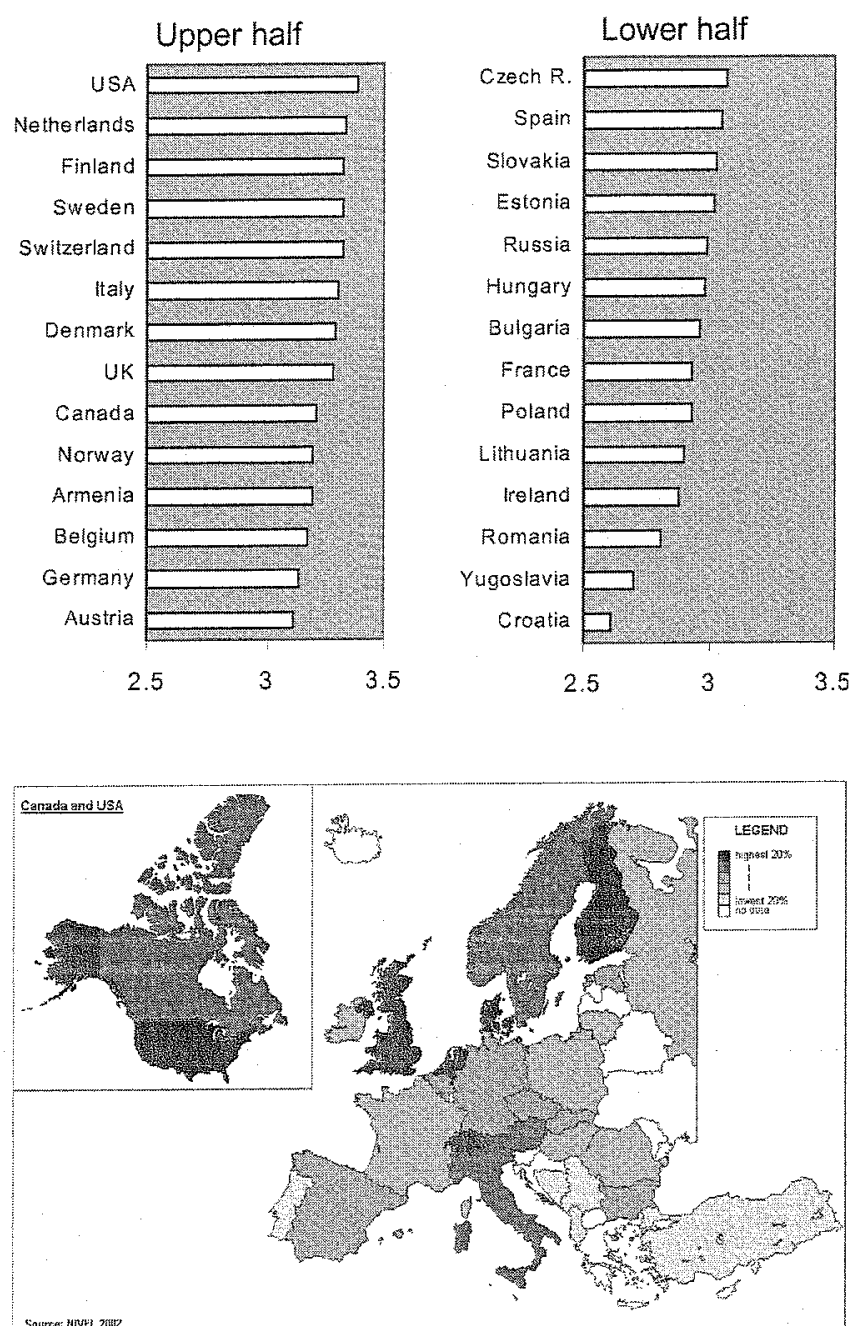


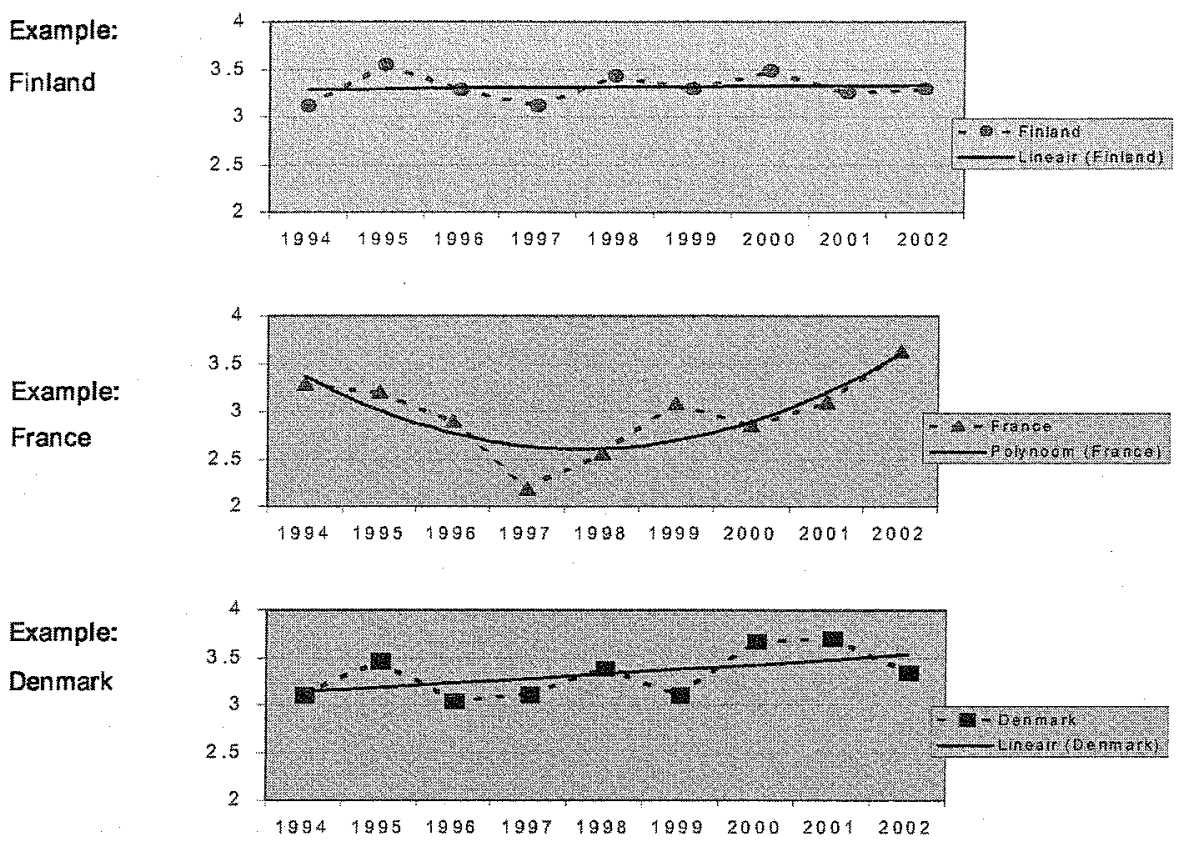

Fig. 8. Development patterns over time for selected countries

slightly (and decreasingly) around the mean while the ratings for France went down in the period 1994-1997 and raised again from 1998 till 2002. For the other countries the number of abstracts submitted over the years was insufficient to calculate a trend.

\section{Topics of the abstracts}

Of the 1994, 1995 and 2000-2002 abstracts the topic has been coded in 5 broad categories: (1) health services research (2) epidemiology (public health research), (3) health information, (4) health promotion, and (5) methodology. The distribution of the abstracts over the five topics changed over the years. The conferences started under the 'heading' "Health Services Research" (in 1989); so, it was expected that HSR-abstracts would be more prevalent in the first EUPHA-conferences than in the later years. For epidemiology/public health research we expected that this pattern would be reversed, since EUPHA stands for public health, indicating more emphasis on this subject. Graph 9 shows that this is the case, indeed. The other result worth commenting on is the 'boost' of health information in the last years. The Brussels' conference that had been devoted to this topic is clearly responsible for this result. 


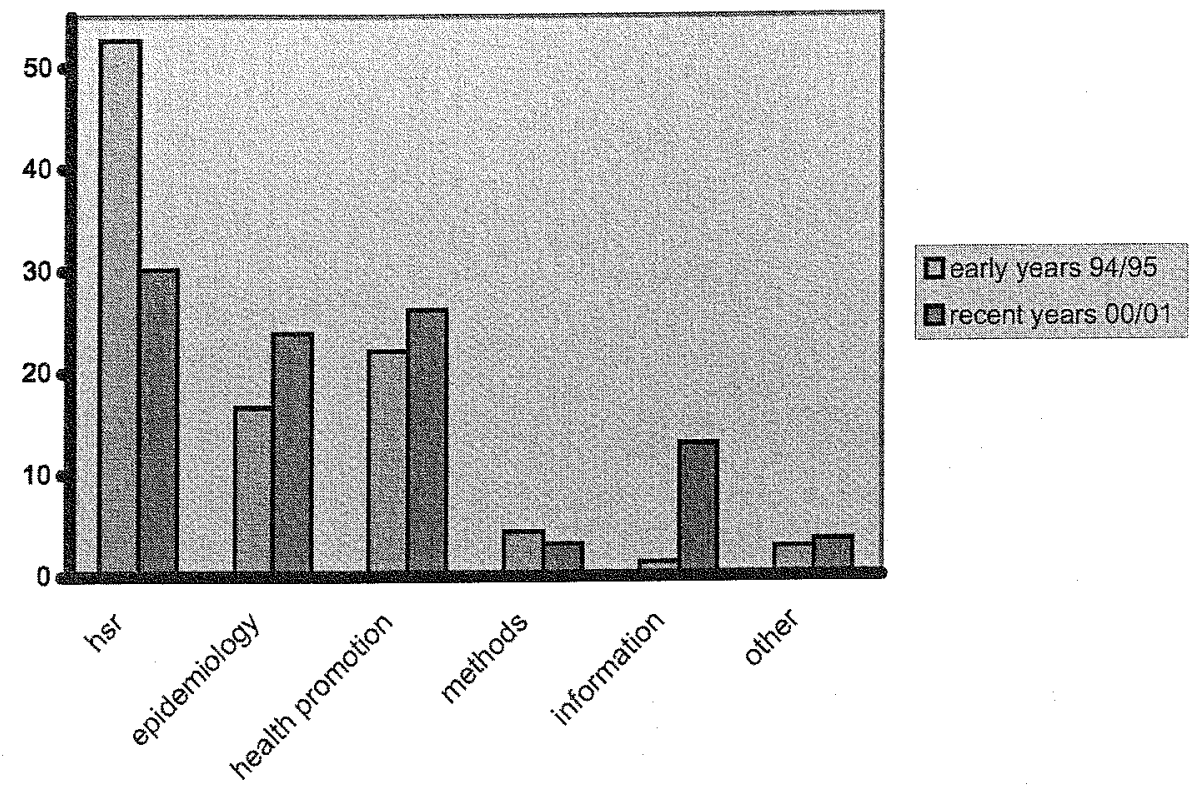

Fig. 9. Shift of interest between early years and recent years conferences

\section{Individual judges}

Judges differ characteristically; some are rather mild, some seem to have vinegar in their veins. Some serve long terms, some participate just for a single conference. Most of them judge only a part of the abstracts ${ }^{6}$; some seem to take pride in judging them all (one of our colleagues suggested that this might have a relationship with the quality of the judge's marriage, however, we do not have any information on this).

In order to get an idea, Graph 10. shows the average ratings over the years of a handful of judges, who took part of the jury for at least 5 years.

It is clear that there are mild and strict judges, but the average ratings differ per conference.

There does not seem to be a tendency over time. It is possible that judges adapt their score to the general level of the contributions. Responsiveness is the correct term for this phenomenon. We cannot say much about this responsiveness because we do not have a 'golden standard'; abstracts have not been scored repeatedly by the same judges at different moments in time. There is one question we can answer about the judges. As we explained in the introduction, there are two types of judges: permanent and ad-hoc members of the scientific committee. As the ad hoc members are local, their ratings could differ from the permanent members. In Graph 11 ratings of judges that participated only one year are compared with judges that participated at least five years: the 'old hands ${ }^{7}$.

\footnotetext{
${ }^{6}$ In order to avoid that the first half of the abstracts get more ratings than the last half, the judges are explicitly asked to start judging at a specific abstract number; as the number of abstracts fluctuates between 300 and 400 , the total number usually is split into two or three groups; e.g., one third of the judges will start with $n \mathrm{r} 1$, one third will start with $\mathrm{nr} 150$ and one third with $\mathrm{nr} 300$.

${ }^{7}$ We used the number of years as a proxy; one year only for a local member; over four years for an experienced 'permanent' judge.
} 


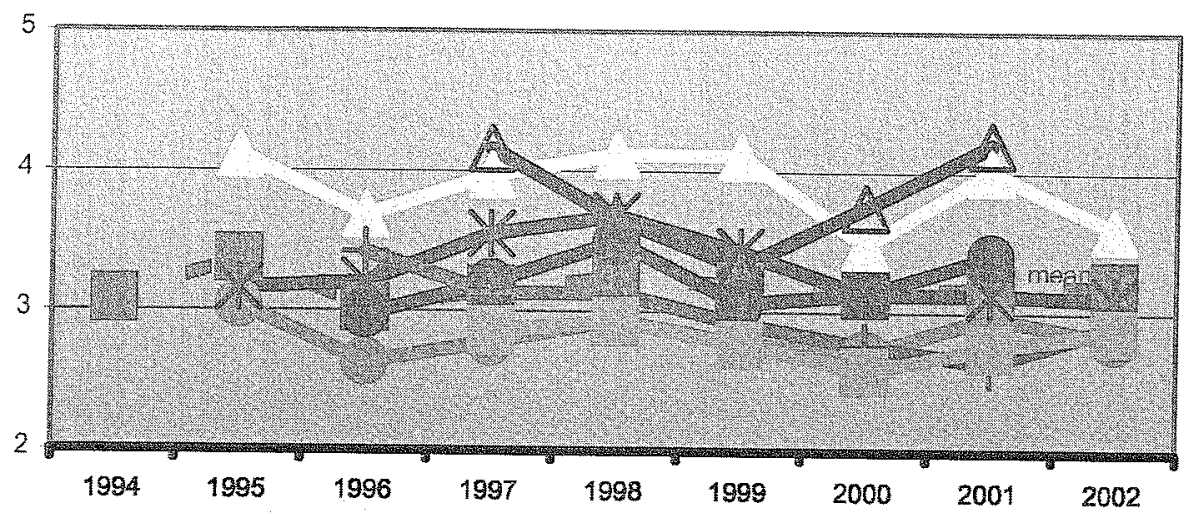

Fig. 10. Scores of several judges that participated in the process for 5 years or more
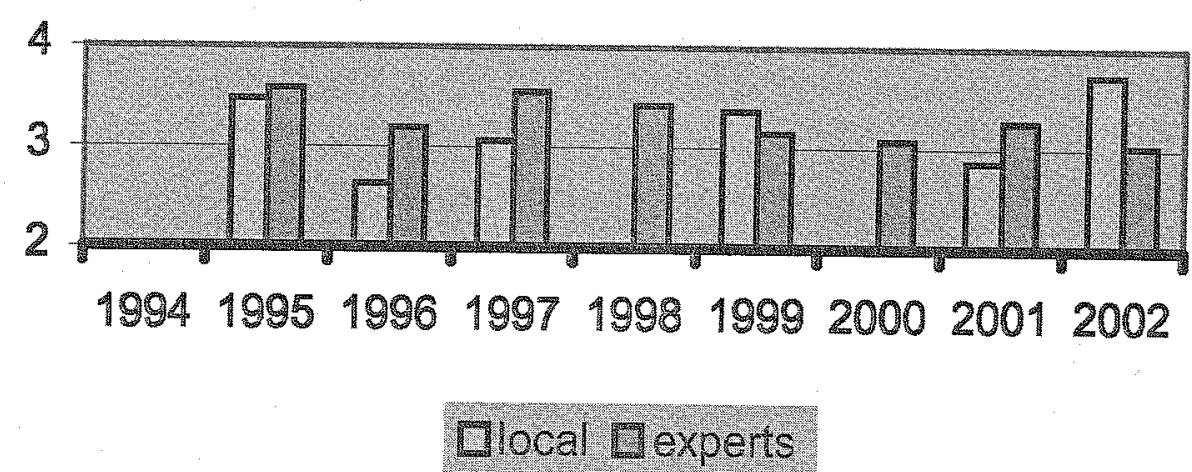

Fig. 11. Differences between local ( 1 year participation) and experienced ( 5 years or more) judges

In some cases (the Prague and Dresden conference for instance) the local judges scored more favourably than the experienced judges; in other cases (the Brussels conference is a good example) the opposite happened. The overall result does not allow a clear conclusion; the ratings of local, ad hoc judges do not differ systematically from experienced judges.

\section{Distinguishing 'bad' from 'good' abstracts}

For the answer to the last research question "can we answer the question what distinguishes a 'good' from a 'bad' abstract" a selection of the abstracts (all the abstracts of 1994, 1995 and 2000, 2001 and 2002) were rated according to the set of topics described in the method-section of this paper. The ratings related to the general format and structure of the abstract, to the design of the study and to the topic of the study. Two multiple regression analyses were performed (ordinary least squares) both with the average ratings of the abstracts (that is the average of all the judges per abstract) as dependent variable and two sets of predictors. The first set consists of the following abstract characteristics:

1. follows guidelines for structured abstract, yes/no

2. quantitative (ref category), qualitative study or don't know

3. descriptive (ref category), non-systematic comparison, systematic comparison 
4. local, national (ref category) or international study

5. fits this year's conference motto (yes/no)

6. fits last year's conference motto (yes/no)

7. topic: health services research (ref category), epidemiology, health promotion, health information or methodology

8. disease related study (yes/no)

Most of the categories are self-evident; some need some further explanation.

Ad 1) follows guidelines or not; most abstracts follow the 'background-aim-method - result-discussion' scheme, some, however do not.

Ad 2) Most studies are explicitly quantitative; some are qualitative or a combination of both. In some cases the design could, unfortunately, not be established.

Ad 3) Research implies comparison (before/after, between subgroups etc.). Many studies are descriptive. Some are systematically comparative, in this case it is known in advance which groups or conditions will be compared. Some studies end up with comparative results (gender differences, SES differences) that were not mentioned in advance. This latter group of design has been dubbed 'non-systematic comparative'.

Ad 4) The scope of a study (local, national or international) is rather self-evident; some categories of studies (reviews for instance) could not be classified into the localinternational continuum.

Ad 5, 6) Self evident.

Ad 7) Under the topic 'epidemiology' the incidence or prevalence of (self-assessed) health or illness and/or the occurrence of health related risk factors (health determinants) are comprised. Health information includes databases, electronic medical files and health statistics. Health promotion deals with actions to improve health or combat illness. The other factors are self-evident.

Ad 8) Disease related studies might encompass a specific illness or a group of diseases.

To this set of variables two extra variables were added for the second analysis: the year of the conference (to test whether the average rating increased or decreased over time) and the region (North West (ref category), West central, South, East and non-European). The expectation was that the influence of the variables of the first set would disappear (at least partially) with the introduction of the regional variables. We expected that the higher rates for instance abstracts from. North-West Europe was due to the fact that these were more often quantitative, better structured, comparative etc.

The results of the regression analysis are shown in Table 1.

Comparing both analyses it is striking that adding region of the abstract does not alter the results of the first analysis, where region had been left out. Adding year did not change the results and did not contribute to the explained variance. So it is not true that abstracts from North-West Europe get higher scores because they are better structured or less descriptive or quantitative rather than qualitative compared to abstracts from the other regions. The region factor refers to other elements than those already measured. The year of the conference does not matter; abstracts for early conferences do not receive lower or higher marks than abstracts submitted to more recent conferences.

A high scoring abstract

1. follows the guidelines

2. does not follow this year's conference motto but last year's conference motto

3. is quantitative rather than qualitative

4. is internationally comparative and not local

5. is not descriptive but (systematically) comparable 
Table 1. Multiple regression analysis of determinants of abstract quality*

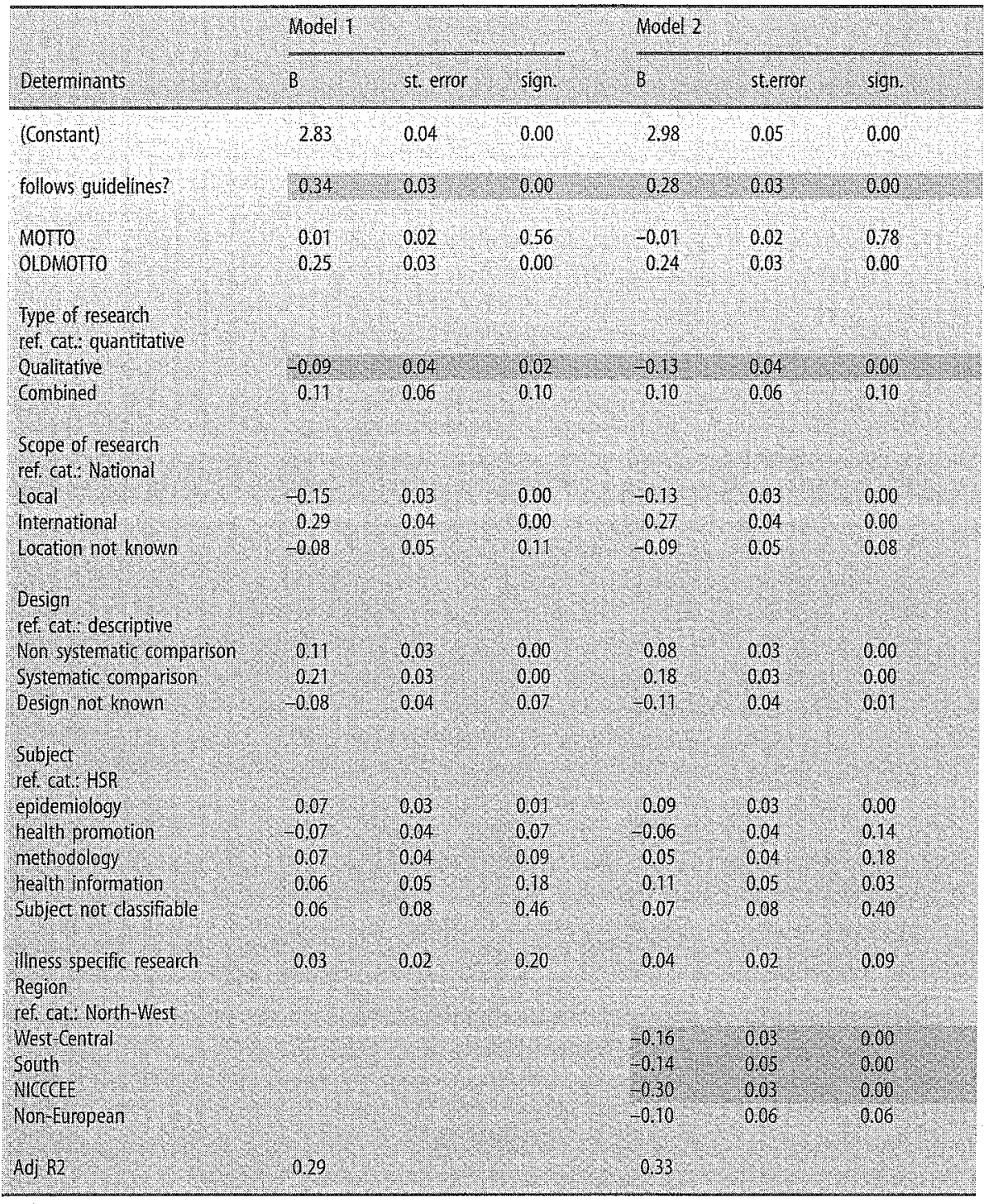

*) Areas indicate significance levels of $p>0.05$. Dependent variable is mean score of each abstract. 
6. focuses on (determinants of) health rather than health services research

7. is written by a North-West European first author rather than by an Eastern European

\section{Discussion}

It seems worthwhile to keep the scoring and submission records of conference abstracts. Even this preliminary analysis gives some quantitative insight in the dynamics of the abstract scoring procedure. It also seems to be worthwhile to score the abstract forms on relevant dimensions; good ratings are, to some extent, predictable.

The quantitative scoring system with multiple judges forms a solid and time saving base for decisions about rejection or acceptation of abstracts. The conference organizers adopted this method from the British Society of Social Medicine in 1991 and it can be recommended to all conference organisers. Although some judges have systematically lower scores than others, the fact that one abstract is scored by about 5 to 10 judges makes the change of only 'sour' judges quite low.

Why this year's motto does not and last year's motto does influence the rating positively, we do not know. A possible explanation could be that criteria for abstracts that are not typical research abstracts are established after the conference organizers are confronted with a substantial set of them. So, the criteria to judge 'health information abstracts' or 'public health practice' abstracts appeared after the Brussels conference of 2001; they were published in the 2002 - call for abstracts. We are also puzzled by the fact that the introduction of the 'region' does not explain away the coefficients in the first analysis. We had expected that abstracts from North-West Europe would have got higher rates because they were better structured, rather quantitative than qualitative, rather comparative than descriptive etc. This does not seem to be the case; introducing the 'region-factor' does not reduce or even alter the previously found coefficients; it adds explained variance of its own.

We do not know which specific predictors hide behind the broad region factor. We have been toying with an idea, but rejected it because of the complex data collection it required; It might be the case that some research received lower rates because it did not add much to the existing knowledge, although the studies might have flawless designs. Some studies show that social health inequalities also exist in Hungary or the Czech republic, because studies were repeated for the first time for these countries. The same goes for smoking prevalence in Georgia or food habits in the Baltics. In our analysis, we did not rate whether a study contributed something new to the domain of research. That would have required a much more complicated data collection.

\section{Limitations of the study}

This study is a typical first analysis, driven by curiosity. Literature about quality assessment of research should be included. In fact, a fourth research question should have been added, that reads as follows: 'How valid and reliable is the abstract evaluation process?' Corrections for inter-judge variances could improve real insight into the quality of the abstracts. There might be relevant interactions between year, region and other abstract characteristics, but these were not included in the analysis. The reliability of the ratings of the abstracts by the authors of the paper is not perfect and could have been improved. This may be a recommendation for future research. 
The legibility of the abstract was scored low only when it was literally illegible (due to e.g. fax problems) or completely incomprehensible. It may be so that a more refined scale, making a distinction between abstracts in fluent English and those where authors struggled with the language, would contribute to the evaluation of the judges. It would have been nice if lists of conference participants had also been kept and computerized. Now all statements about 'participation' are based on submitted abstracts.

One should notice that the study should not be taken too seriously. It gives an intriguing insight and that is it. Therefore we end with 'lessons for the future'. Based on the results of the regression analysis abstracts can be optimized. The regression analysis provides Hints for an ideal abstract that will be shown below.

\section{Lessons for the future: how to optimize my abstract}

Lesson 1: have an author from North-Western Europe as first author; borrow a colleague if you happen to live in the East or South (or organise a fellowship in one of the more favourable countries).

Lesson 2: follow the instructions; use the background, aim, method, results, discussion scheme.

Lesson 3: Have a quantitative design, preferably internationally comparative and not locally.

Lesson 4: Avoid descriptive studies; tell in advance (that is: in the introduction) which groups or situations you are going to compare and why.

Lesson 5: Do a study about health and not about health care (personally the authors would deplore if you did, but it helps a bit if you want to optimize your rate).

Good luck next year!!!!

\section{Other recommendations}

In order to promote the scientific development and information exchange from Eastern European countries, the conference might be more often organised in these countries. For instance, the NEWS circulation scheme (see introduction) could be changed in NEWES. Our analyses showed that the conferences lead to a higher participation of those coming from the organizing country.

The fact that the average score of the abstract is around three could interpreted as the outcome of a solid judgement method. However, since the scores are on a 5-point scale, from psychological literature it is known that persons tend to locate their score around the thee. To force judges into a choice for a more positive or negative judgement, a six-point scale could be introduced. (A minor drawback of this is of course that there will be a trend-break in the data, which implies that an analysis like this has to wait another 10 years to be carried out). 
Table 2. Scoring form for content analysis

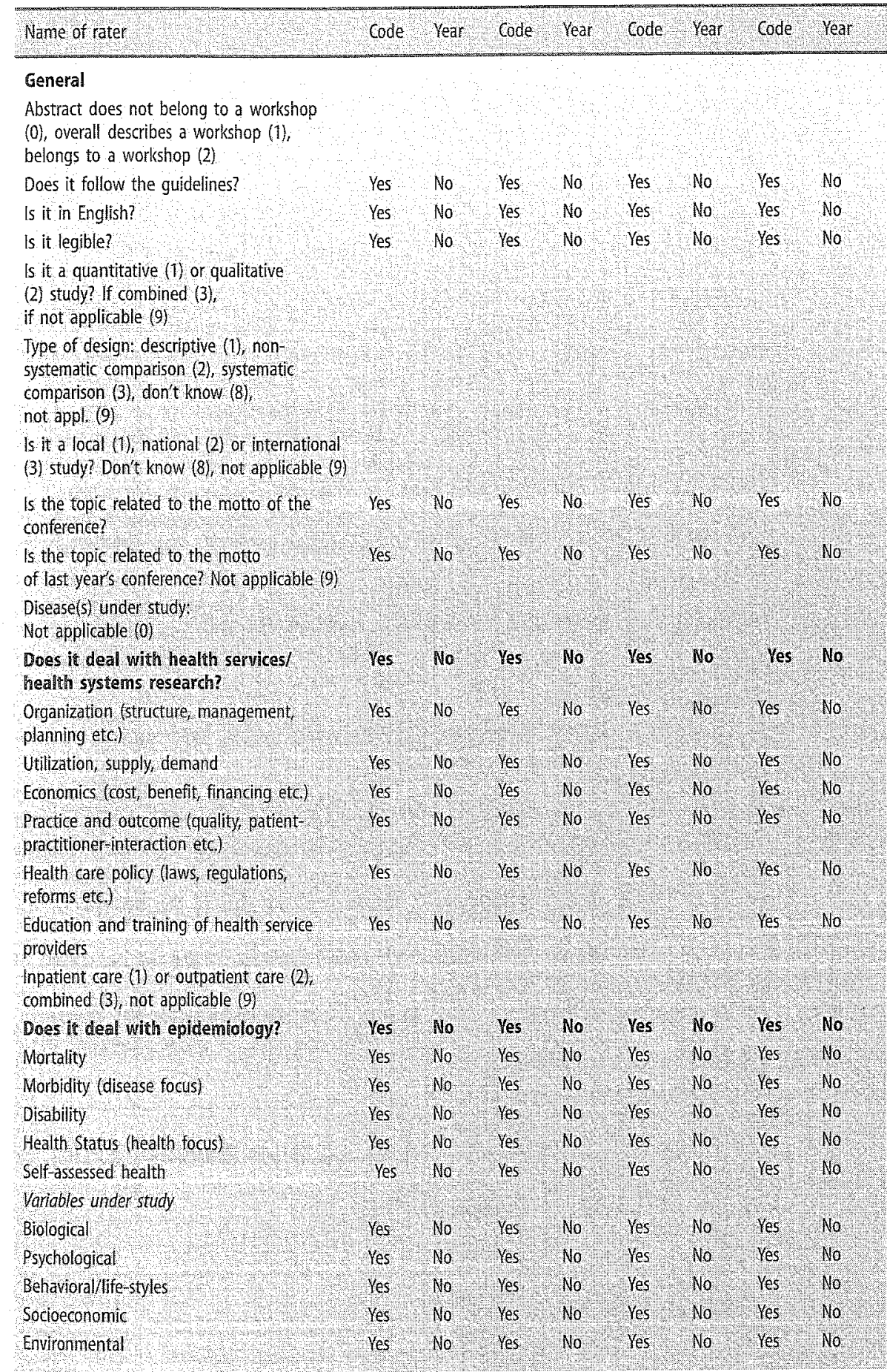


Table 2 (continued)

\begin{tabular}{|c|c|c|c|c|c|c|c|c|}
\hline Name of rater & Code & Year & code & Year & Code & Year & Code & Year \\
\hline \multicolumn{9}{|l|}{ General } \\
\hline Does it deal with health promotion? & Yes & No & Yes & No & Yes & No & Yes & No \\
\hline Health education & Yes & No & Yes & No & Yes & No & Yes & No \\
\hline Public health policy & Yes & No & Yes & No & Yes & No & Yes & No \\
\hline $\begin{array}{l}\text { Does it deal with methods (data } \\
\text { collection, measurement, indicators...) }\end{array}$ & Yes & No & Yes & No & Yes & No & Yes & No \\
\hline Does it deal with health information? & Yes & No & Yes & No & Yes & No & Yes & No \\
\hline Databases & Yes & No & Yes & No & Yes & No & Yes & No \\
\hline EMD & Yes & No & Yes & No & Yes & No & Yes & No \\
\hline
\end{tabular}

Other (if the abstract does not fit into one of the above main categories please give a short description, indicate code_year!)

\section{Coding instructions (revised)}

Code_Year: If an abstract has the number 11 and belongs to the 1994 abstracts, fill in $11 \_94$ for code_year. Always copy the complete abstract number (e.g. poster 5_94, chr17_95).

Mottos of the conferences:

1994: Epidemiology, Prevention, Health Policy, Health Services Research

1995: Public Health Research, Policy and Practice and Health Care Reforms

2000: Reduction of Health Inequalities. Nutrition and Health

2001: Health Information/Policy

2002: Bridging the gap between research and policy in public health. Information, promotion and training

Please assign one abstract to one of the main categories only (these are: Health Services Research or Epidemiology or Health Promotion or Methods or Health Information or Other). If the abstract seems to belong to two categories, choose the one that it mainly belongs to. Only if no clear decision can be made, it can be assigned to two main categories. This should be the exception however. Please indicate this at the bottom of the form (in the 'other'-field).

If an abstract e.g. makes a comparison between several regions, it should be coded as (1) local instead of (2) national.

- Diseases are coded according to the ICD-10. Please fill in the code(s) for the disease(s) as listed below (maximum 3 diseases, separate with commas, if more diseases mentioned: code 99).

1 Certain infectious and parasitic diseases

2 Neoplasms

3 Diseases of the blood and blood forming organs and certain disorders involving the immune mechanism

4 Endocrine, nutritional and metabolic diseases

5 Mental and behavioural disorders

6 Diseases of the nervous system

7 Diseases of the eye and adnexa

8 Diseases of the ear and mastoid process

9 Diseases of the circulatory system

10 Diseases of the respiratory system 
Table 3. Themes of the conferences

\begin{tabular}{|c|c|c|}
\hline Location & Year & Theme \\
\hline Copenhagen & 1994 & Epidemiology, prevention, health policy HSR \\
\hline Budapest & 1995 & Pub health research, policy and practice/health care reforms \\
\hline London & 1996 & Evidence-based pub, health policy and pract, \\
\hline Pamplona & 1997 & Health of the regions \\
\hline Göteborg & 1998 & New technology and public health \\
\hline Prague & 1999 & A decade of health care reforms \\
\hline Paris & 2000 & Reducing inequalities/hutrition \& health \\
\hline Brussels & 2001 & Health information systems \\
\hline
\end{tabular}

11 Diseases of the digestive system

12 Diseases of the skin and subcutaneous tissue

13 Diseases of the musculoskeletal system and connective tissue

14 Diseases of the genitourinary system

15 Pregnancy, childbirth and the puerperium

16 Certain conditions originating in the perinatal period

17 Congenital malformations, deformations and chromosomal abnormalities

18 Symptoms, signs and abnormal clinical and laboratory findings, not elsewhere classified

19 Injury, poisoning and certain other consequences of external causes

20 External causes of morbidity and mortality

99 More than three diseases

If the abstract does not deal with a disease, please fill in a for not applicable! 



\title{
European Journal of Public Health and EUPHA - 10 years on
}

\author{
Martin McKee
}

\section{Why a European Journal of Public Health?}

Anniversaries provide an opportunity for reflection. Where have we come from? Where are we going? And why are we here? My task is to reflect on these questions as they relate to our journal, the European Journal of Public Health.

The first question, where have we come from, is the easiest one to answer. We began as an idea by my predecessor, Per-Gunner Svensson, who identified the need for a public health journal with a particular European focus. Of course there were already many national public health journals, and even some regional ones, such as the excellent Scandinavian Journal of Public Health. At that time the Journal of Epidemiology and Community Health was still largely a British journal, although it has since been transformed under the outstanding editorship of Carlos Alvarez and John Ashton. And of course there were the many more specialised journals in areas such as epidemiology, economics and so on. But at a time when borders were opening all across Europe, whether through the Schengen Agreement within the European Union or the Treaty of Paris, which marked the end of the cold war, there was a clear gap in the market for a specifically European multi-disciplinary perspective.

The rest is history. The journal had predated the creation of EUPHA but once EUPHA was established the benefits of partnership were apparent. The European Journal of Public Health became the official journal of EUPHA. Since then the journal has prospered. While recognising the limits of bibliometric measures, and in particular their inherent bias against non-American journals [15], we can be comfortable, while never complacent about our steadily increasing impact factor. We are also indexed in MEDLINE, bringing our content to a much larger audience.

\section{Adapting to a changing world}

The next question is where we are going? This is more difficult to answer. The journal occupies an unusual niche. In an increasingly commercial publishing environment it simply does not fit into the usual mould. By distributing copies to the very large membership of EUPHA it saturates the potential market in Europe. Not unreasonably, many libraries ask why they should subscribe to the journal when they know that they can obtain copies from staff of their institution who are members of EUPHA. This is, of course, great for the journal's ability to reach a wide audience but hopeless for its finances. Although we have a respectable number of subscriptions from universities in other parts of the world, in particular in North America, we have to accept that, in the USA, where the main market for biomedical journals lies, we face a huge barrier simply because of the lack of interest among most Americans in things that take place in other parts of the world [1]. 
We are also constrained by our method of distribution, with costs borne by the national associations. This means that we cannot easily do what we clearly should if we are to become more timely or to accept a greater number of the many good papers we are now forced to reject. It also makes it difficult to go further beyond the increasingly oldfashioned model of a journal as something that simply publishes those papers that are sent to it, never thinking about what else it can do for its readers by stimulating discussion and debate or bringing them news.

This is why EUPHA is now reassessing the nature of its journal. I am convinced there will always be a case for journals printed on paper, at least until someone develops a light weight computer display that can safely be read in the bath, but we also need to recognise that access to the internet among potential readers is now virtually universal. Ten years ago the idea that someone in Novosibirsk or Kishinev might have easy access to an electronic journal published in the west was unimaginable. Yet increasingly, in countries that missed out on the expansion of static telephone lines during the $1960 \mathrm{~s}$, individuals are jumping to new forms of mobile internet access. The world is changing incredibly rapidly and we must ensure that we meet the challenges involved.

The internet offers also offers advantages to those who interact with journals as authors and referees, with an increasing number enabling electronic submission and on-line reviewing. But all of these things cost money, something that we, with our current financial resources, can only dream of.

Yet a paper copy still has many advantages, apart from the ability to read it in the bath. The amount of information available on the internet is immense but how much of it do we ever access? A journal is more than simply an archive of data to be consulted when needed. It also has a role to communicate emerging ideas and prompt debate. If that paper copy no longer drops through our letter box, will we really go to the trouble of looking for it? And what will this mean for the sense of identity that we seek to engender among members of EUPHA, for whom the only connection is often the annual meeting. In other words, how can we grasp the potential advantages of the new technology, without loosing the benefits of the old? Until we answer these questions we can only speculate as to where we will go in the future.

\section{A distinctively European contribution}

So we can easily answer the first of our questions, where have we come from? We have more problems with the second one, where are we going? But then, those who predict the future with confidence are often proved wrong [2]. But what of the third question, why we are here?

This is the question that is the most important? What need is there for a distinctive European journal of public health? This apparently simple question raises two issues. One is what it means to be European? The second relates to the nature of public health. We will examine each in turn.

The definition of Europe has long been a subject of exam questions in history and political science. International organisations offer little help. The European Union has expanded from six to the present fifteen countries, and is on the verge of a further expansion that could bring it to 25 . This expanded body would include some countries such as Turkey, most of whose territory is in Asia, while excluding countries such as Norway and Switzerland that are clearly European, at least in terms of geography. It also includes places that are geographically very far from Europe, such as French Guiana on the north east coast of South America, and la Reunion, in the Indian Ocean, by virtue of their status as 
departments outré mer of France, while excluding Danish possessions such as Greenland and British ones such as the Channel Islands. So clearly the European Union cannot take our understanding very much further.

What about WHO? Its European Region inherited the states that constituted the Soviet Union, so it now encompasses countries such as Turkmenistan, with its historical links to Iran, and Tajikistan, which has much in common with Afghanistan. It also includes Israel, but not Lebanon, purely for wider geopolitical reasons.

But maybe this is the wrong paradigm? Maybe Europe is less a geographical expression, as Metternich once disparagingly referred to Italy, but rather it is an idea? Perhaps it is a shorthand for a set of collective values that distinguish those who inhabit a certain piece of this earth from those who inhabit other places? [7]. As the history of Dresden, where this conference is being held, reminds us, this suggestion would have been ridiculed 60 years ago. Then, my country, the United Kingdom, was at war with this one, Germany. Terrible things were done on both sides in the struggle for supremacy of different sets of values and beliefs. This city suffered further over the following 45 years, as the Soviet empire sought to impose its values on this part of a defeated Germany, and on its neighbours to the south and east. Anyone who doubts the benefits of breaking down barriers in Europe should come to Dresden and see why this is important. And it is only since 1990, with the breaking down of the barriers that divided us that we have been able to appreciate what Mikhail Gorbachev referred to as our common European home.

But what does this mean in practice? It is all too apparent that the diversity within Europe is still immense. We speak different languages. We eat different foods. We play different sports, and we find different things amusing. These differences give us a unique advantage as a massive laboratory for understanding the determinants of disease and the effectiveness of different types of policies in tackling them [3]. The observation that heart disease is very much less common in Spain or Italy than it is in Denmark or the UK has led to important insights into the benefits of the Mediterranean diet. One of the greatest contributions that this association has made is to help us come together to look at each other, compare how we share common problems, and learn from our different degrees of success and failure.

For we do have much in common, although often this only becomes clear when we compare ourselves with others. And it is particularly obvious when we compare ourselves with the other major industrialised system, the USA.

This comparison is often particularly difficult for those like myself who live in the United Kingdom. We speak the same language, sort of, even if we pronounce the words differently. The massive penetration of our media by American products, the pervasive presence of American fast-food outlets, and the continuing attempts by some British politicians to win the race with Puerto Rico to become the fifty-first state often causes a crisis of identity, which is especially apparent at times like the present, when Downing Street has reinvented itself as a branch of the State Department.

But we should not allow this to obscure the profound differences, many of which are central to public health. I believe that the journal provides us with a real opportunity to demonstrate our common European values, values that we share with one another regardless of other political differences. One very obvious example is respect for life. All countries in Europe are united in their belief that the state should not deny criminals their right to life. Abolition of the death penalty is a prerequisite for membership of both the European Union and the Council of Europe. It is, fundamentally, a core European value. The USA, in contrast, executes not only those people who are both guilty and aware of what they did, but it is also among the handful of countries to execute those who were teenagers when they committed their crimes, or whose mental capacity was such as to prevent them from understanding what they were doing. A few years ago we published an edi- 
torial on the death penalty [14]. But what has this to do with a journal of public health? I believe it has a lot to do with it. It is but one example of where we, as Europeans, have something to say. We can use our journal to draw attention to the injustices that persist because of the retention of the death penalty in some countries.

But Europe is different in other ways. Take health care. All countries in Europe have found some way to ensure universal health care coverage [10]. The way they do it may differ and the fairness with which they redistribute resources may vary. But they still manage to ensure that almost everyone can receive timely and effective health care. This is not the case everywhere else. As a consequence we have published many papers on health and equity and, in particular, we have encouraged studies that have cast light on those who are often least visible in our societies, the migrants who come to our countries fleeing persecution just as many Europeans fled from totalitarian regimes in Europe, seeking refuge in America in previous generations [6].

\section{Taking a wider perspective}

We also try to see the big picture. From the earliest days it was recognised that promoting health involves a struggle. This was seen, typically, as our struggle against infections and their vectors. While the poor are disproportionately afflicted by infectious disease, its unpredictability means that everyone is at risk, and it can even bring down political systems. As Lenin noted, "If communism does not destroy the louse, the louse will destroy communism". The struggle between humans and infections is never-ending; the challenge is to keep one step ahead of the microorganisms. This requires constant vigilance and the implementation of policies that tackle the reasons why infections get ahead of the curve. These policies require an international effort and here too we have encouraged papers that look at the scope for collaboration within Europe and world wide [13].

But the leading threats to health are no longer confined to micro-organisms. Death is now being spread by other vectors. Reflecting its role as the leading cause of premature death in Europe, we feature many papers on tobacco. Tobacco is spread by an agent as dangerous as the rats and fleas that brought plague to Europe in the fourteenth century, by an agent, the tobacco industry, that shares many features with the rats that spread plague, although I realise that some rats may resent the comparison.

We became involved with this agent of death a few years ago when we published a paper by an author who, unbeknown to us, while occupying an academic post at a leading Swedish university, was a paid consultant to the tobacco industry [4]. Since then this has become the subject of legal action in Switzerland [11]. As part of this process we have had the privilege of helping to expose the web of secret financial transactions that have allowed the tobacco industry to take advantage of the activities of a small number of academics who continue to seek to discredit the now well-established link between passive smoking and premature death.

Earlier I was somewhat critical of the United States, but this is an issue where we have benefited by learning from our American colleagues, in particular Stan Glantz, at San Francisco, who is one of the true heroes of public health because of his relentless fight against the tobacco industry, regardless of the risk to himself [8]. The work that he and his colleagues did in making available the tobacco industry's internal documents was invaluable to us. Hopefully more researchers in Europe will follow his example, casting light on how the tobacco industry is thinking so that much more effective interventions can be developed to combat them. As the recent article in Stern magazine about the extensive links between the tobacco industry and senior figures in Germany showed [12], there is much to be done on this side of the Atlantic. 
Of course some questions have no easy answers. Readers must make up their own minds. But we can try to help by providing the information in a way that facilitates comparison. One recent example, albeit rather technical, was a series of papers that looked at risk adjustment in competing social insurance systems [9]. Another recent commentary looked at the challenges facing epidemiology as it strives to go beyond the relatively easy questions, such as does smoking cause lung cancer to the more difficult ones, where exposures and outcomes are far more difficult to define and where interactions abound [5].

In this article I have argued that the European Journal of Public Health can be more than simply another public health journal. We have sought to ensure that we publish a wide range of original research, from a broad range of disciplines and perspectives, and from a wide range of countries. But we also try to see ourselves as, to some extent, a voice for European public health. However it is our readers who must judge whether we succeed.

Acknowledgements: The success of the journal is a reflection of the dedication of my colleagues on the editorial team: Anita Kallin, Staffan Janson, Carlo La Vecchia, and Johan Mackenbach, as well as Dineke Zeegers-Paget (EUPHA), Claire Saxby (Oxford University Press) and Tineke de Jong-Bijlmer (Z-Stijl).

\section{References}

1. Esler G (1998) The United States of Anger: The People and the American Dream. Penguin, Harmandsworth.

2. McKee M (1995) 2020 Vision. J Publ Health Med; 17: 127-31.

3. McKee M (1998) An agenda for public health research in Europe. Eur J Publ Health; 8: 3-7.

4. McKee M (2000) Smoke and mirrors: clearing the air to expose the tactics of the tobacco industry. Eur J Publ Health; 10: 161-163.

5. McKee M (2001) Epidemiology in the 21st century: the challenges ahead. Eur J Publ Health; 11: 241-2.

6. McKee M, Janson S (2001) Forced migration: the need for a public health response. Eur I Publ Health; $11: 361$.

7. McKee M (2002) Values, beliefs and implications. In: Marinker M (ed). Health targets in Europe. BMJ Books, London. pp 181-205.

8. Maurice J (2000) Stan Glantz, tobacco warrior. Bull WHO; 78: 947.

9. Saltman RB (2001) EJPH Policy Forum: risk adjustment strategies in three social health insurance countries. Eur J Publ Health; 11: 121.

10. Saltman R, Figueras J (1997) European Health Care reform: Analysis of current strategies. World Health Organization, Copenhagen.

11. URL: http://www.prevention.ch/rylanderpm.htm

12. Wedemeyer G (2002) Kämpfer für den Qualm. Stern, 31 Oct.

13. Weinberg J, Grimaud O, Newton L (1999) Establishing priorities for European collaboration in communicable disease surveillance. Eur J Publ Health; 9: 236-240.

14. Weish J (2000) The death penalty as a public health issue. Eur J Publ Health 2000; 10: 2-3.

15. Zetterstrom R (2002). Bibliometric data: a disaster for many non-American biomedical journals. Acta Paediatr; 91: 1020-4. 